\title{
Effects of Crustal Structure under the Barents and Kara Seas on Short-Period Regional Wave Propagation for Novaya Zemlya Explosions: Empirical Relations
}

\author{
by Tianrun Zhang and Thorne Lay
}

\begin{abstract}
Short-period seismic recordings at regional and upper mantle distances from underground explosions at Novaya Zemlya demonstrate that propagation across the continental shelf under the Barents and Kara Seas appears to modify the partitioning of energy between $L_{g}$ and $S_{n}$ phases relative to purely continental paths in the Eurasian crust. While the underwater segments of the paths are relatively short, variations in bathymetric characteristics from path to path influence the regional wave field, with systematic behavior that can be used to establish empirical amplitude corrections for regional phases. We analyze a large set of Eurasian recordings to explore the relationship between regional phase energy partitioning and bathymetric characteristics. Maximum water depth along the path is the most influential factor for the Novaya Zemlya data. It has strong linear correlations with the logarithmic rms amplitude of $L_{g}$ and the ratios $S_{n} / L_{g}$ and $P / L_{g}$. The maximum water depth probably reflects the extent of necking of the crustal wave guide under the continental margin, which may disrupt $L_{g}$ modes resulting in $L_{g}$ to $S_{n}$ scattering, but there is surprising sensitivity to small variations in bathymetry. Empirical relations like those found here may be useful for nuclear yield estimation and discrimination for regions such as the Korean Peninsula and Persian Gulf, where many seismic phases traverse water-covered continental shelf with poorly known crustal structure.
\end{abstract}

\section{Introduction}

The short-period regional seismic phase $L_{g}$, comprised of Rayleigh wave overtones or postcritical multiply reflected $S$ waves, has long been known as a "continental phase." In fact, its first applications were for discriminating continental and oceanic crust based on the presence or absence of the $L_{g}$ phase, respectively (Press and Ewing, 1952). Oliver et al. (1955) used such bimodal classifications to investigate the crustal structure in the Arctic, while Savarensky and Valdner (1960) studied the Black Sea region. These studies concluded that in no case does $L_{g}$ propagate through crust overlain for any significant distance by water deeper than 1000 fathoms $(1.8 \mathrm{~km})$. Thin oceanic crust is now well known to inhibit $L_{g}$ propagation (e.g., Kennett and Mykkeltveit, 1984), but the effects of transitional crustal structures are not as clear.

It was quickly recognized that propagation across a marginal sea or continental shelf does not completely quench $L_{g}$, but can reduce its amplitude. A number of studies have been conducted for $L_{g}$ traversing paths under shallow water. Wetmiller (1974) investigated the crustal structure in the Baffin Bay area, and Gregersen (1984) studied the crustal structure near Denmark and the North Sea. Kennett et al. (1985) then examined heterogeneity of the North Sea basin using variability of $L_{g}$ transmission. Recently, Baumgardt (1990) explored $L_{g}$ blockage and scattering by the Barents Sea and White Sea, recognizing the importance of energy partitioning between $L_{g}$ and $S_{n}$ in the regional wave field. He inferred that the presence of thick sedimentary basins plays a critical role in $L_{g}$ blockage. Nuttli (1988) analyzed $L_{g}$ phases on similar paths across the Barents Sea, with only moderately strong attenuation values being found for the blocked arrivals, and their relative yield-amplitude scaling appearing to be unimpaired. Theoretical studies of propagation across continental margins have been conducted by Kennett (1986), Maupin (1989), Regan and Harkrider (1989), and Cao and Muirhead (1993). The latter study used $P-S V$ finite difference calculations to demonstrate that necking of the crust and the presence of the thin water layer can effectively block $L_{8}$. Many additional studies have examined variations in $L_{g}$ and $S_{n}$ 
transmission efficiency in diverse continental environments (e.g., Ruzaikin et al., 1977; Kadinsky-Cade et al., 1981; Ni and Barazangi, 1983; Lynnes and Baumstark, 1991).

These important studies have provided insight into the complex structural controls on $L_{g}$ in a heterogeneous transitional crust, but we still lack a practical means by which to account for the strong amplitude and spectral effects of underwater segments for regional arrivals. This is particularly important for efforts to monitor underground explosions of low yield and to discriminate them from earthquakes using regional phases. The strong variability of regional discriminants (e.g., Pomeroy et al., 1982; Lynnes and Baumstark, 1991) mandates correction for path properties affecting regional phase amplitudes and spectral content.

The water in most parts of the North Sea, Barents Sea, and Kara Sea is shallower than $200 \mathrm{~m}$. The thinning of the crustal wave guide under the shelf is small (except in the central rift of the North Sea) relative to the typical 30- to 40-km thickness of the adjacent continental crust. However, $L_{g}$ waves do have highly variable transmission efficiency through these water-covered regions. This implies that there must be significant changes in the crustal structure or in the shallow sediments underlying the marginal seas that affect the regional wave field.

This study explores the influence of the bathymetric structure of the Barents Sea and Kara Sea on regional phase propagation. The approach taken is an empirical one, given that current capabilities for realistically simulating regional waveforms are quite limited, as is our detailed knowledge of the regional crustal structure. One of the major obstacles confronting nuclear nonproliferation monitoring is the variability of regional wave energy flux associated with diverse paths in the crust. If it is possible to develop reliable empirical approaches that use surface observations such as path topography or bathymetry to account for some of the wave field variability, more effective procedures for global monitoring may be achieved. For example, Zhang and Lay (1994) have recently discovered surprisingly strong empirical relationships between regional phase-amplitude ratios and along-path topography statistics for Eurasian continental paths. In this spirit, our analysis involves seeking simple path parameters that provide a basis for reducing wave field variations associated with propagation through the crustal structure underlying a shallow sea. Quantitative modeling of any such relationships will be pursued in the future.

\section{Data}

The seismic data that we use are recordings of 20 underground nuclear explosions located in the Novaya Zemlya test site near Matochkin Shar (the narrow strait that separates the northern and southern islands of No- vaya Zemlya). The events occurred from 1964 to 1988 . Short-period regional and upper mantle distance recordings from Soviet-run stations were collected and digitized for these events as part of a data exchange associated with the Joint Verification Experiment. The locations of the test site and stations providing sufficient numbers of recordings and instrument response information for our analysis are shown in Figure 1. Topography contours for Eurasia are included, derived from digital elevation data supplied at 5-min intervals from a world topography data base (ETOPO5, compiled by the National Geophysical Data Center, Boulder, Colorado). The stations range in distance from 1900 to $3600 \mathrm{~km}$, and provide the most extensive data set for Novaya Zemlya explosions available from the Eurasian mainland. Most previous studies of short-period regional phases from explosions at this test site have used array data from Norway, Germany, and Finland (e.g., Baumgardt, 1990; Ringdal and Fyen, 1991) or from isolated stations in western Europe and Scandinavia (Nuttli, 1988), which sample a very restricted azimuthal range from the test site. The exchange data provide an extensive data set with broad azimuthal coverage, including paths with diverse underwater segments.

Figure 2 shows detailed bathymetry of the region around Novaya Zemlya, with the Barents Sea to the west and the Kara Sea to the east. The ray paths to the exchange stations sample different paths through these marginal seas. This provides a basis for exploring the relative waveform effects of different underwater segments. The previous work on Novaya Zemlya regional data mentioned above has primarily used paths traversing the deeper water regions of the Barents Sea (toward the west in Fig. 2).

Only vertical-component seismograms have been digitized for the exchange stations, but the general signal quality is quite good (Israelsson, 1992). Altogether, 108 waveforms from the 20 explosions recorded by eight stations are used in the analysis. The instrumentation is comparable between stations, but there are slight variations in frequency response, as well as variations with time at each station. To equalize the instrument characteristics, we deconvolved the individual instrument responses from each waveform, and then convolved the ground motion with the 1988 response of the CKM-3 seismometer at station OBN. For some of the data, portions of the records are missing; we use only the phases which are reliably digitized. Many details about the specific explosions, the exchange data set, and the signal quality are given by Israelsson (1992). We combine data from different events to characterize average path properties, and so do not dwell on the individual event information.

Our primary interest is to explore whether energy partitioning in the regional wave field is influenced by the variation in underwater path segments. To achieve 
this, we require robust measurements of the short-period wave field. Previous studies have established the stability of gross averaging measures such as rms calculations for regional phases (e.g., Ringdal et al., 1992; Hansen et al., 1990; Israelsson, 1992; Zhang and Lay, 1994), so we use comparable measurements in this study. The rms values for different phases were calculated using the instrument-equalized traces, with bandpass filtering between 0.6 and $3.0 \mathrm{~Hz}$. These frequency limits conform to routine regional phase passbands used by Hansen $e t$ al. (1990) and are compatible with the limitations of the hand-digitized data.

The rms amplitudes of each phase are calculated in corresponding group velocity or time windows. The $L_{g}$ is assigned the window 3.1 to $3.7 \mathrm{~km} / \mathrm{sec}$, following Israelsson (1992), while the $S_{n}$ window is 4.3 to $4.8 \mathrm{~km} /$ sec, as preferred by Kennett (1989) (see Fig. 4 for an example). We found that use of a narrower $L_{g}$ window of 3.1 to $3.5 \mathrm{~km} / \mathrm{sec}$ had only minor effects on the measurements in this study. We use time windows for the $P$ waves, which at the upper mantle distances spanned by our data have impulsive first arrivals followed by complex coda. We use both $0-$ to 5- and 0- to 50- $\mathrm{sec}$ windows from the onset of the $P$ arrivals. The latter part of the 0 - to 50-sec window contains an increasing component that is multiply reflected within the crustal wave guide, but the primary energy dives into the upper mantle. A noise correction was applied to each measurement (Zhang and Lay, 1994), obtained from the rms amplitude of the available signal prior to $5 \mathrm{sec}$ preceding the manually picked $P$ onset (usually $115 \mathrm{sec}$ of data). A comparably measured data set for underground explosions at the Semipalatinsk test site, comprised of 325 waveforms for 83 explosions from the JVE exchange (Zhang and Lay, 1994) is used for comparison with the Novaya Zemlya observations. The paths associated with those data are indicated in Figure 1.

\section{Characterization of Paths}

The islands of Novaya Zemlya are an extension of the Ural mountains, commonly identified with the

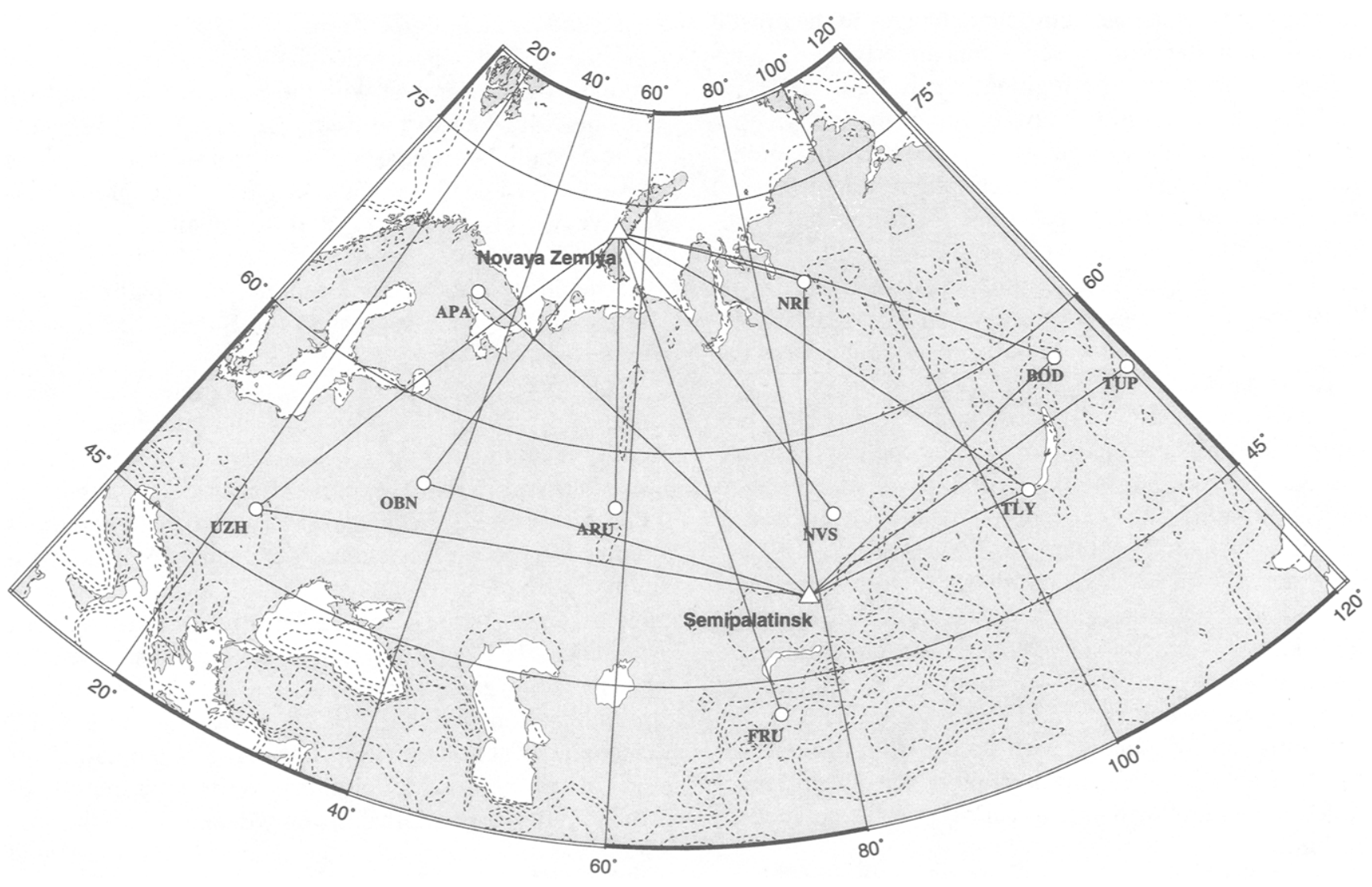

Figure 1. Map showing the locations of the Novaya Zemlya and Semipalatinsk test sites, marked with triangles, and the seismological stations used, marked with circles and indicated by their codes. The lines between the sources and receivers correspond to great-circle paths. Topography is indicated with contour intervals every $1000 \mathrm{~m}$ from -1000 to $3000 \mathrm{~m}$ above sea level, but $500 \mathrm{~m}$ contour is added to show Ural and other low mountains. Plotting software from Wessel and Smith (1991) is used in this and the next two figures. 


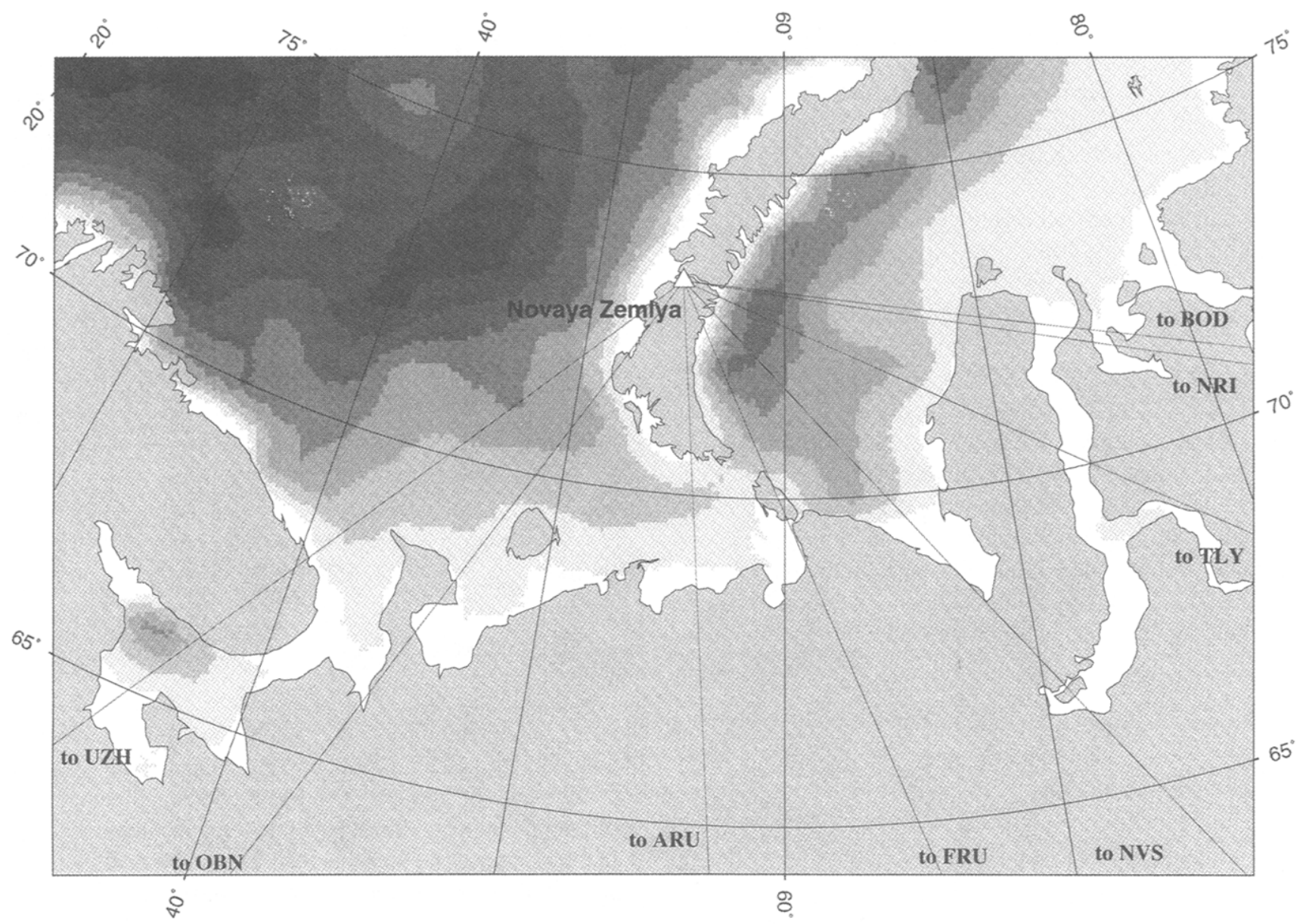

Figure 2. Map showing bathymetry around Novaya Zemlya, and great-circle paths from the test site to each Eurasian station used. The contour interval assigned to each gray-shade is $50 \mathrm{~m}$. The Barents Sea is to the west of the island, and the Kara Sea to the east. The paths traverse the continental shelf with depths ranging from $50 \mathrm{~m}$ to a maximum of $350 \mathrm{~m}$ (east of the island).

Table 1

Bathymetric Statistics of the Paths

\begin{tabular}{lcccc}
\hline Path & Mean Depth $(\mathbf{m})$ & Length $(\mathrm{km})^{*}$ & Max. Depth $(\mathrm{m})$ & Area $\left(\mathrm{km}^{2}\right)^{\dagger}$ \\
\hline BOD & 111 & 420 & 341 & 46.9 \\
NRI & 108 & 420 & 338 & 45.3 \\
TLY & 126 & 420 & 278 & 52.8 \\
NVS & 116 & 590 & 337 & 68.4 \\
FRU & 220 & 280 & 340 & 61.6 \\
ARU & 41 & 230 & 116 & 9.5 \\
OBN & 6 & 450 & 129 & 27.1 \\
UZH & 87 & 710 & 171 & 61.7 \\
\hline
\end{tabular}

*Total underwater length.

$\dagger$ Cross-sectional area of the underwater segment.

boundary between Europe and Asia. The eight paths from Novaya Zemlya to Eurasian stations sampled by our data are readily divided into two groups. Three paths, to UZH, OBN, and ARU, cross the southeast Barents Sea (Fig. 2), where the maximum water depth is 100 to $150 \mathrm{~m}$. We call this the Barents group. There is a relatively deep- water zone off the east coast of Novaya Zemlya, in the southern Kara Sea. Paths to FRU, NVS, TLY, NRI, and BOD traverse this deeper water, where the maximum depth is about $300 \mathrm{~m}$ (Fig. 2). This is the Kara group. Each path has slightly different underwater segment characteristics, which we will consider. These include mean depth, total underwater length, maximum depth, and the cross-sectional area of the underwater segment, the values for which are given in Table 1.

The entire propagation path influences the regional wave field, and in this case all of the paths have significant segments across the Russian platform. While details of the crustal structure on each path are at best very sketchy, a possible guide to relative structural characteristics is provided by surface topography. The topography profiles, from the ETOPO5 data base with $10-\mathrm{km}$ lateral sampling, are shown for each path in Figure 3. The island source region is on the left of each profile and the station is on the right. There is a large vertical exaggeration, but in most cases the underwater segments 
are minor features relative to the continental relief along the paths.

The path to BOD has a mean water depth of $111 \mathrm{~m}$, and a maximum water depth of $341 \mathrm{~m}$, similar to the other four paths in the Kara group. The pathlength across the sea is $420 \mathrm{~km}$. We do not include the pathlength under shallow water bodies along this path like Obskaya bay and Yeniseyskiy gulf. The western half of the BOD on-land path is flat, on the Siberian lowland. When the path intersects the Vilyuyskoye Plateau, the altitude rises and the surface becomes quite rough. On the basis of the work by Zhang and Lay (1994), we anticipate that this topography will reflect changes in the wave guide that affect the propagation of regional phases, although possibly not as dramatically as the underwater segment. The path to NRI almost coincides with the west half of the BOD path, ending just before the rough topography begins. The path to TLY is similar to that to BOD, with the southern segment encountering rough topography in the Sayan mountains. The path to NVS has a long un-
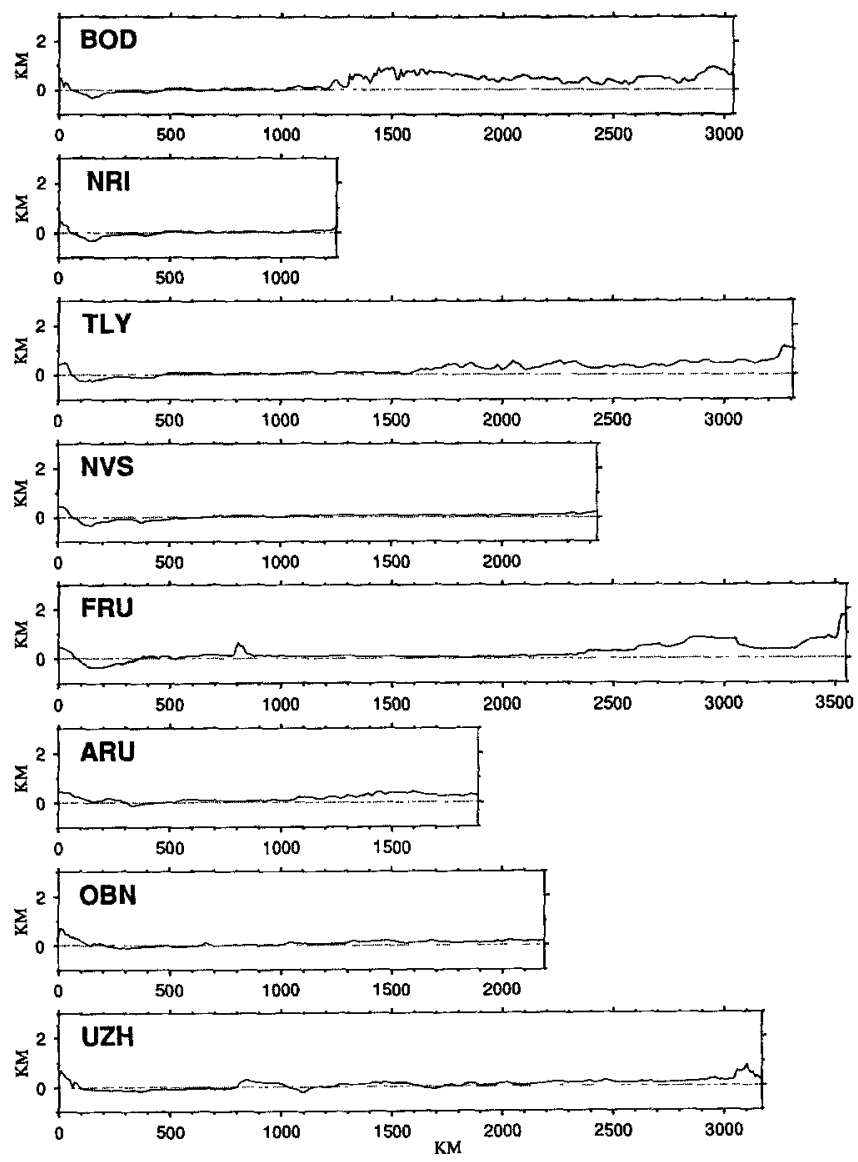

Figure 3. Profiles of surface topography from the ETOPO5 data base along paths between the Novaya Zemlya test site and the eight Eurasian stations shown in Figure 1. The units of horizontal and vertical axes are both kilometers, but the vertical scale is exaggerated by a factor of 110 . The dotted lines are sea level. derwater segment, as it traverses Baydaratslaya bay, the southernmost part of the Kara Sea. The on-land segment is quite flat. The path to FRU has the greatest mean water depth $(220 \mathrm{~m})$ and a maximum depth of $340 \mathrm{~m}$ (Table 1). Its on-land segment crosses the Ural mountains and then traverses the huge Siberian plane, before encountering the high-altitude Pamir mountains. Unfortunately, there is only one record available from FRU.

The paths of the Barents group have relatively shallow underwater segments. The path to ARU runs along the Ural mountains for a few hundred kilometers, which is likely to affect the regional phase propagation. The path to OBN has a very shallow mean water depth and a flat on-land path. The path to UZH has the longest underwater segment $(710 \mathrm{~km})$, but the mean depth is only $87 \mathrm{~m}$. This path crosses the White Sea and Lake Ladoga, but we have only summed the pathlength under the Barents Sea.

\section{Examination of Path Effects}

Oliver et al. (1955) observed clear $L_{g}$ arrivals at a station in Copenhagen from an earthquake located in the Arctic Ocean, with a path that crosses the Kara Sea, Novaya Zemlya Island, and the Barents Sea. Their conclusion, and all other lines of evidence, indicate that the crust underlying these two seas is essentially continental. The water depth between Novaya Zemlya and the Eurasian mainland is never more than $350 \mathrm{~m}$, and $L_{g}$ energy is not totally blocked. Yet, we find that traversing the underwater segment appears to substantially modify the energy partitioning in the short-period regional wave field, as has been previously demonstrated for paths to Europe (e.g., Baumgardt, 1990). The clearest evidence for this is provided by comparison of Novaya Zemlya recordings with Eurasian recordings of events at other Soviet test sites.

In order to evaluate the effects of the underwater paths, we compare the seismograms from Novaya Zemlya events with recordings of Semipalatinsk explosions from the same Eurasian stations. The latter involve almost entirely on-land paths (Fig. 1). Figure 4 shows representative waveforms at similar distances for recordings of a Novaya Zemlya event at station OBN (top) and a Semipalatinsk event at the same station (bottom). To emphasize the relative energy distribution in the short-period signals, the times scales are modified to have common group velocity scales from 9.0 to $2.8 \mathrm{~km} / \mathrm{sec}$. The general structural characteristics of each path, as manifested in surface topography and geologic provinces traversed, are quite similar, apart from the short underwater segment for the Novaya Zemlya data (Fig. 1). The waveform from the Semipalatinsk event has a clear $L_{g}$ wave packet in the group velocity window of 3.7 to 3.1 $\mathrm{km} / \mathrm{sec}$, with a maximum near $3.5 \mathrm{~km} / \mathrm{sec}$. The $S_{n}$ window has very weak energy, indistinguishable in this 
passband from the $P$ coda. The $L_{g}$ window for the Novaya Zemlya event has lower signal to noise ratio but there is clearly energy in the interval. There is relatively high-amplitude energy in the latter part of the $S_{n}$ window. The corresponding path traverses the shallowest water segment amongst the various Novaya Zemlya paths, but even in this case the overall difference in the shortperiod energy distribution is apparent.

The differences seen in Figure 4 are common to the large data sets for each test site. To illustrate this we use a simple measure, picking the group velocity at which each waveform amplitude peaks in the range 5.0 to 2.8 $\mathrm{km} / \mathrm{sec}$. Comparisons of such measurements for a large suite of explosions at the two sites are shown in Figure 5. Crosses indicate the group velocity of the peak rms amplitude in a moving 8-sec window for Semipalatinsk recordings, while circles are for Novaya Zemlya data. Almost all Semipalatinsk measurements are within the 3.7 to $3.1 \mathrm{~km} / \mathrm{sec}$ range, corresponding to the $L_{g}$ window. However, most Novaya Zemlya measurements are in the 4.6 to $3.8 \mathrm{~km} / \mathrm{sec}$ range, which is the latter part of the $S_{n}(4.8$ to $4.3 \mathrm{~km} / \mathrm{sec})$ window, and in what Zhang
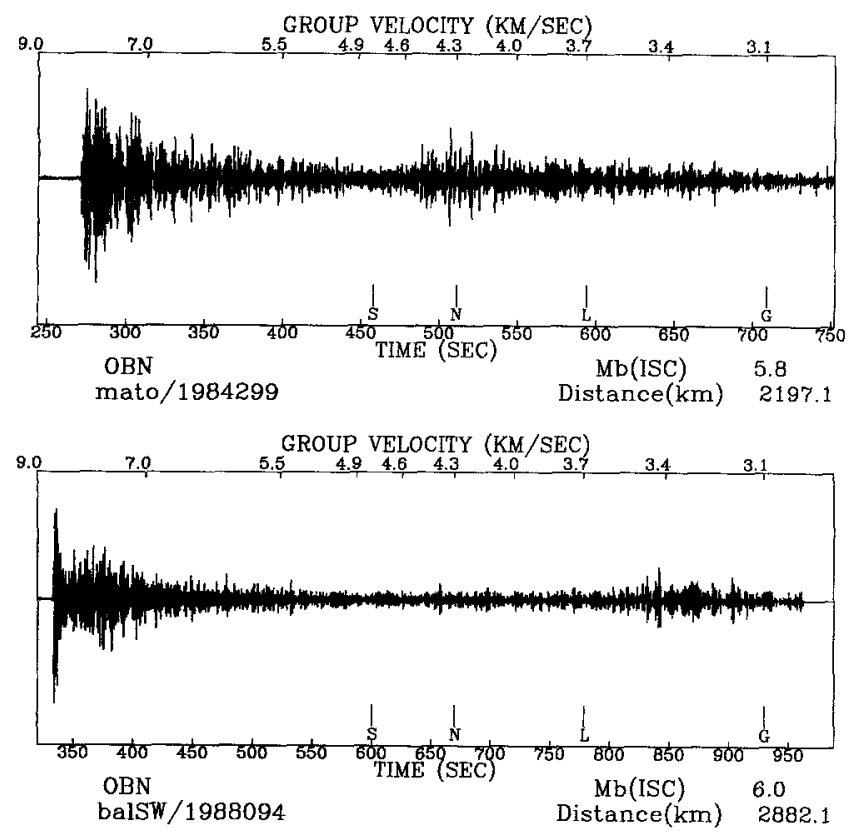

Figure 4. Representative seismograms for recordings on the Semipalatinsk-OBN path (below) and the Novaya Zemlya-OBN path (above). The waveforms are bandpass-filtered between 0.6 and $3.0 \mathrm{~Hz}$. The time scales are slightly different so that the two signals, which are at different distances from the sources, can be put on the same group velocity scale (indicated at the top of each plot). The vertical lines mark the windows used to calculate rms amplitudes. The $S$ to $\mathrm{N}$ interval corresponds to the $S_{n}$ window of 4.8 to $4.3 \mathrm{~km} /$ sec, and $L$ to $G$ indicates the $L_{g}$ window of 3.7 to $3.1 \mathrm{~km} / \mathrm{sec}$. Notice the relatively strong $S_{n}$ for the Novaya Zemlya event recording. and Lay (1994) define as the $S_{n}$ coda window (4.3 to 3.7 $\mathrm{km} / \mathrm{sec}$ ). While the separation is on average very clear, despite the variety of paths involved, there are a few interesting exceptions. For the Semipalatinsk data, the two records on the path to APA have peak amplitudes at group velocities higher than $4.0 \mathrm{~km} / \mathrm{sec}$. This path is very long and unusual in that it traverses the White Sea just before reaching the station (Fig. 1). Although the maximum depth of the White Sea is only $48 \mathrm{~m}$, the fact that $S_{n}$ is larger than $L_{g}$, as is observed for Novaya Zemlya records, is noteworthy. For the Novaya Zemlya data, some of the records at stations ARU and FRU have peak amplitudes at low group velocities. These paths are close to the underwater extension of the Ural mountains, where the crust is likely to be relatively thick.

The distance ranges spanned by the Semipalatinsk and Novaya Zemlya recordings are comparable, but there are some differences in the amplitude variations of the regional phases with distance. For Novaya Zemlya, the rms amplitude in the $S_{n}$ window of 4.8 to $4.3 \mathrm{~km} / \mathrm{sec}$ is considerably enhanced relative to Semipalatinsk data. In Figure 6, squares indicate the mean rms $S_{n}$ amplitudes from Semipalatinsk, while circles are for Novaya Zemlya. The values are computed after equalizing the event

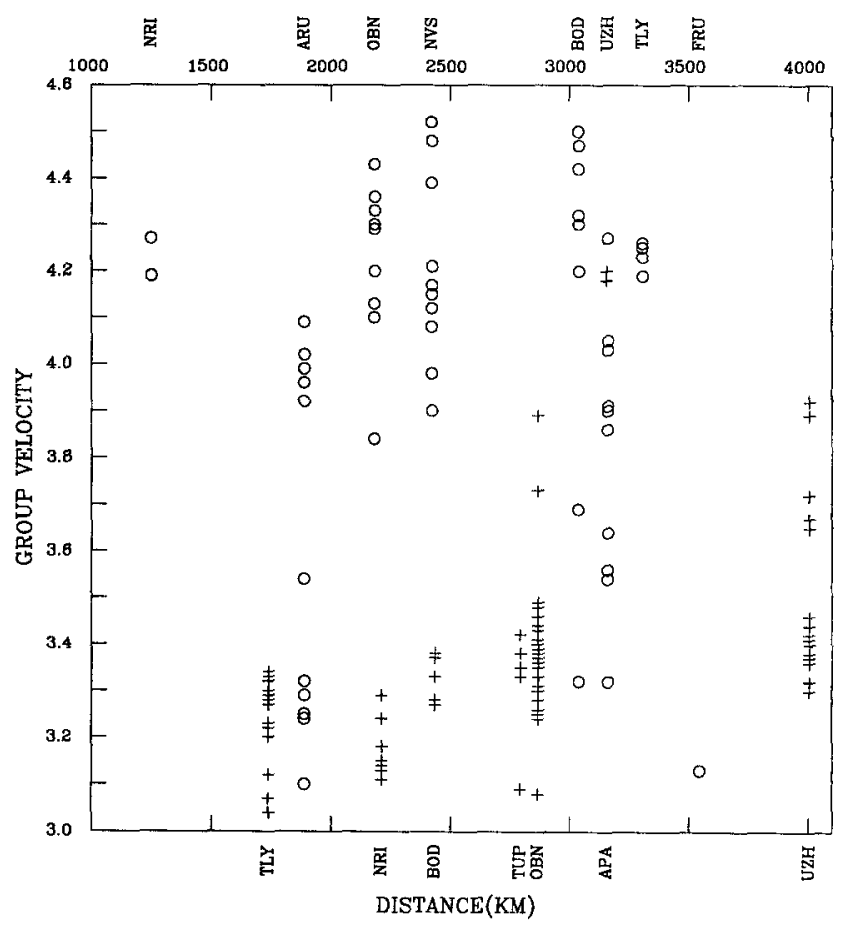

Figure 5. A summary plot indicating the group velocity at which a running average amplitude in an 8-sec window has a maximum value for each seismogram. The measurements are plotted versus distance from each test site, with circles for Novaya Zemlya data (stations are labeled at the top), and crosses for Semipalatinsk data (stations are labeled at the bottom). The group velocity range considered is from 5.0 to $3.0 \mathrm{~km} / \mathrm{sec}$. 
sizes by scaling the measurements to a common teleseismic $m_{b}$ of 5.0. The $S_{n}$ is generally stronger for the paths that cross underwater segments. Strong $S_{n}$ was observed by Kadinsky-Cade et al. (1981, Figs. 12, 13 of that article), for paths across the Caspian Sea and Black Sea. They found that the attenuation factors for $S_{n}$ and $L_{g}$ are not consistent in that region, but they did not conclude that the $S_{n}$ is enhanced. Baumgardt (1990) suggests that the late $S_{n}$ and $S_{n}$ coda windows may be enhanced for paths traversing underwater segments due to $L_{g}$ to $S_{n}$ scattering, so it is possible that the Novaya Zemlya rms values are enhanced in an absolute sense. It is also clear from Figure 6 that the $S_{n}$ energy for Novaya Zemlya exhibits a different distance decay. Some of the $S_{n}$ observations from Semipalatinsk tend to traverse regions with rough topography associated with the Sayan mountains and lake Baikal (Zhang and Lay, 1994), thus, their amplitudes and distance behavior may be anomalous, relative to the comparatively flat paths for the Novaya Zemlya data.

Similar comparisons of mean rms $L_{g}$ amplitudes on paths for Novaya Zemlya (solid circles) and Semipala-

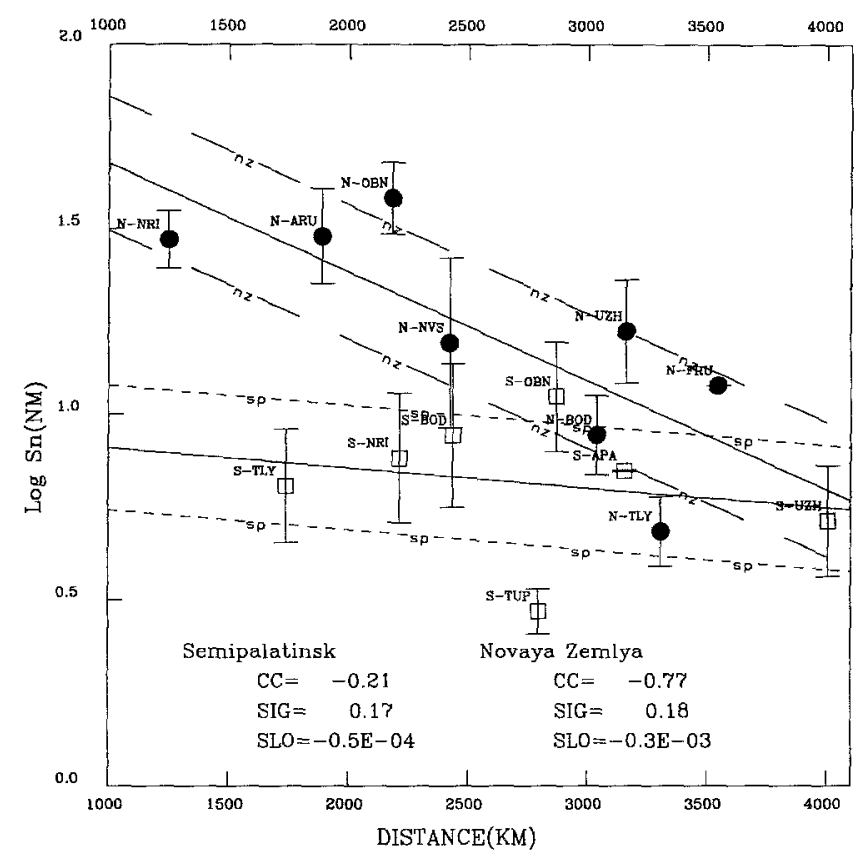

Figure 6. A plot of the mean $S_{n}$ amplitudes and their standard deviations on each path versus path distance, where all events have been equalized to a common $m_{b}=5.0$. Squares are for Semipalatinsk data, and circles are for Novaya Zemlya. The observed $S_{n}$ amplitudes from Novaya Zemlya tend to be higher and show a stronger distance trend. Regressions for the trend with distance are shown. For each regression, $\mathrm{CC}$ gives the correlation coefficient. SIG the standard deviation, and SLO the regression slope. The regression curves are indicated by solid lines. Dashed lines mark the onestandard-deviation limits, $\pm \sigma$. tinsk (open squares) events are shown in Figure 7. The events are again equalized to a common $m_{b}$ of 5.0. The absolute amplitude levels are not systematically different overall, in contrast to the $S_{n}$ measurements; however, the Novaya Zemlya data exhibit somewhat greater variability. We calculated the standard deviation of the distance trends for the $L_{g}$ amplitudes for Novaya Zemlya and Semipalatinsk data separately, finding that the standard deviation for Novaya Zemlya data is about twice that for Semipalatinsk $(0.29$ and 0.14 , Fig. 7). The long and short dashed lines indicate the standard deviations for the two data sets, respectively. Four of the Novaya Zemlya data points, for stations NRI, NVS, BOD, and TLY, are near the lower dashed line. These all belong to the "Kara group"-the deep-water group, and it would appear that on average the $L_{g}$ amplitudes are reduced for these paths relative to the Semipalatinsk data. Of the four Novaya Zemlya points near the upper line, three (ARU, OBN, and $\mathrm{UZH})$ are from the "Barents group"-the shallowwater group. The only exception to this grouping is FRU, for which there is only a single observation. Uncertainty in instrument gains may contribute to some of the scatter in Figures 6 and 7, since some stations tend to plot consistently high or low in each population.

While there are clearly many possible factors influencing these regional phases, we are very limited in our ability to quantitatively model almost all of them, including likely factors such as differences in excitation associated with the near-source properties at the two test sites. We will emphasize the relative, apparently path-

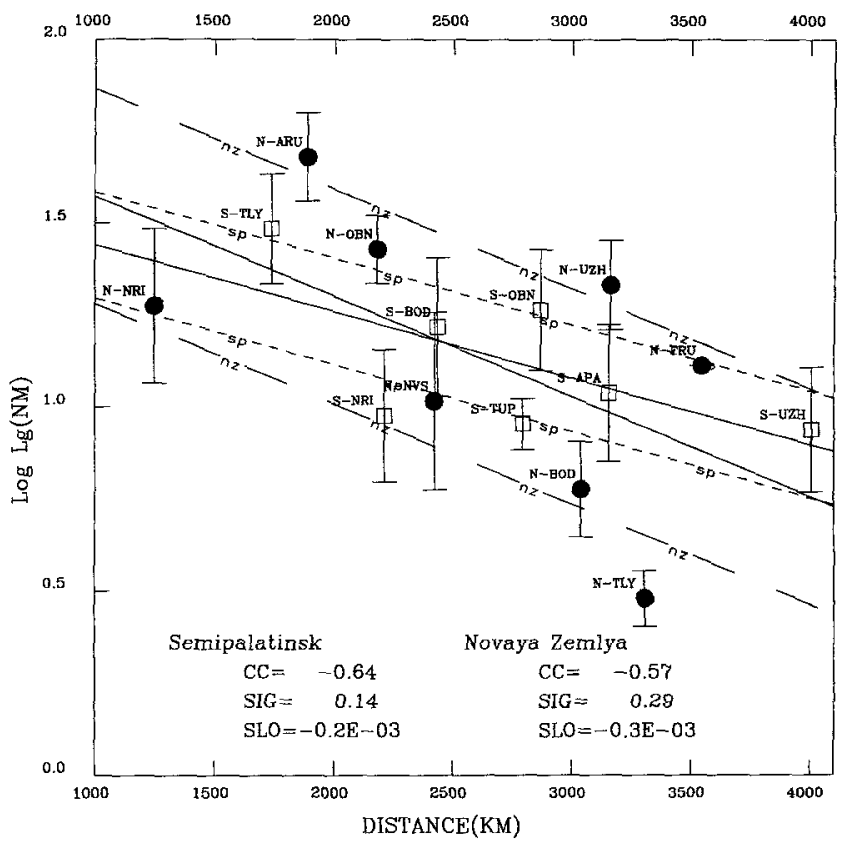

Figure 7. Similar to Figure 6, but for $L_{g}$ amplitudes. The observed $L_{g}$ amplitudes from Novaya Zemlya are scattered more than those from Semipalatinsk. 
dependent variations, as these can be treated somewhat independently of the absolute excitation issues. In previous studies of the Semipalatinsk data set, the $L_{g}$ phase has been demonstrated to be relatively stable (Israelsson, 1992; Zhang and Lay, 1994), but the ratio of $S_{n} / L_{g}$ was found to have a strong correlation with the mean altitude and roughness of the path to each station (Zhang and Lay, 1994). Figure 8 shows the correlation of the rms amplitude ratio $S_{n} / L_{g}$ with average path roughness (standard deviation) estimated from the ETOPO5 data base, for the Semipalatinsk and Novaya Zemlya data separately. Note the very strong correlation for Semipalatinsk, and the relatively large range of roughness sampled by the different paths (details are given in Zhang and Lay, 1994). One interpretation is that the surface roughness provides a surrogate for irregularities of the crustal wave guide, which influence the energy partitioning between $S_{n}$ and $L_{g}$ along each path. In contrast, the Novaya Zemlya data do not show a corresponding relationship, despite the fact that many of the paths traverse similar Eurasian structure. In part, this may reflect the fact that the overall variation in path roughness is reduced for the Novaya Zemlya data set, but we suspect that a more important factor is the variability associated with the differences in underwater segments, which appears to overwhelm the on-land effects. We will test whether we can isolate any such effect.

We use the four underwater path parameters, mean depth, underwater length, maximum depth, and underwater cross-sectional area, tabulated in Table 1, to characterize the variations in shelf segment. Our strategy is to correlate the amplitudes, and amplitude ratios, of each phase with the four factors. Figure 9 shows the result for average rms $L_{g}$ measurements at each station, which have been normalized to a common $m_{b}=5.0$ and then corrected for distance according to power law $r^{-5 / 6}$ (Nuttli, 1973). The latter correction is only for geometric spreading, and ignores effects of attenuation, which will be considered later. Mean depth (Fig. 9a) and underwater area (Fig. 9d) have moderate correlation with $L_{g}$ ampli- tude variations. The length of water segment (Fig. 9b) shows no pattern. Maximum water depth (Fig. 9c) shows the strongest pattern among the four factors, with the Barents group (ARU, OBN, and UZH) clustering on the left, while the Kara group (TLY, NVS, NRI, FRU, and BOD) clusters on the right. The Kara group involves observations spanning a large distance range. A factor of 3 difference in amplitudes is involved, corresponding to the large scatter in Figure 7. Mean depth, maximum depth, and cross-sectional area are all correlated, but it appears that maximum depth is particularly important, more so than the length of the water segment. Mean depth would have a much stronger correlation if the single observation at FRU were omitted.

Very similar results are found for $\mathrm{rms} S_{n}$ amplitudes (Fig. 10). The same geometric spreading correction has been applied to the $S_{n}$ data. The $S_{n}$ amplitude also decreases with increasing maximum water depth, but the amplitude variations are somewhat less than for $L_{g}$.

If wave guide properties associated with water depth are in fact important for the regional wave field, we would expect there to be no correlation with rms amplitude variations in the early part of the direct $P$ arrivals at our stations, which are at upper mantle triplication distances. The $P$-wave coda should involve scattered arrivals, some of which originate in the $L_{g}$ and $S_{n}$ windows, so there could be some sensitivity to the path properties. Figure 11 shows the varying degree of correlation between amplitudes of each phase and the maximum water depth. Because of the upper mantle distance ranges involved, no simple distance correction is realistic for the $P$-wave windows, so in this comparison we make no geometric spreading correction for $S_{n}$ or $L_{g}$. Comparison with Figures 9 and 10 indicates that the geometric spreading corrections used for the latter two phases are actually not very significant relative to the trends found with maximum water depth. Even without any distance correction, $L_{g}$ has the greatest slope and correlation coefficient with maximum depth, followed by $S_{n}$, and then the 0- to 50$\sec P$-wave window, which includes substantial $P$ coda.
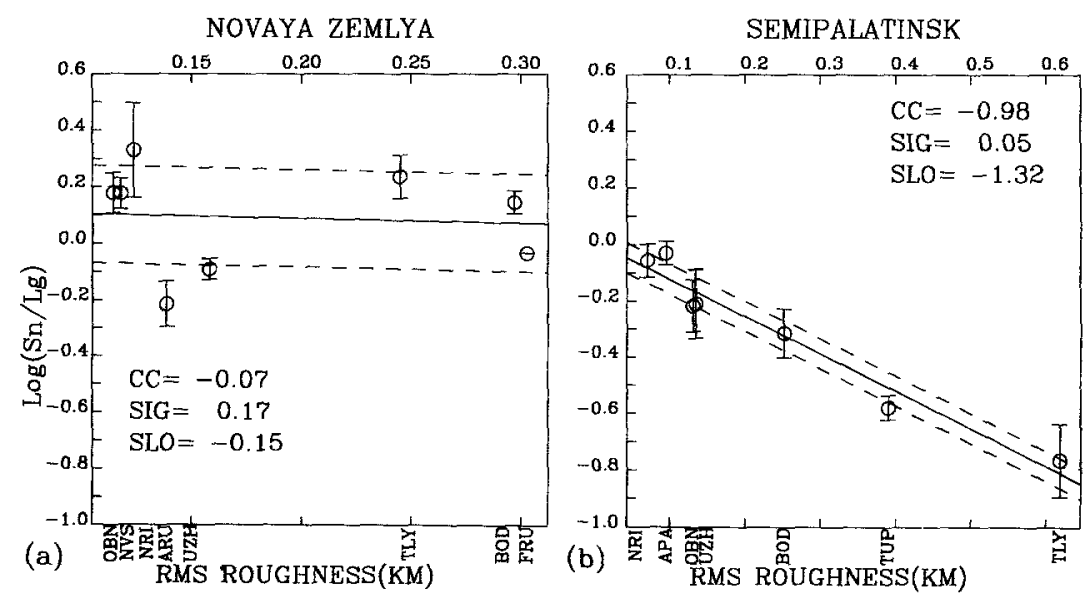

Figure 8. Empirical relation between the rms amplitude ratio of $S_{n} / L_{g}$ versus alongpath topographic roughness (variance) for observations from the Semipalatinsk source region (right) and the Novaya Zemlya source region (left). The strong trend on the right was first reported by Zhang and Lay (1994), and indicates that irregularities in the wave guide structure influence the regional phase energy partitioning. The lack of a strong trend on the left indicates that additional factors, presumably associated with the underwater segments of the paths, dominate in the Novaya Zemlya data. 

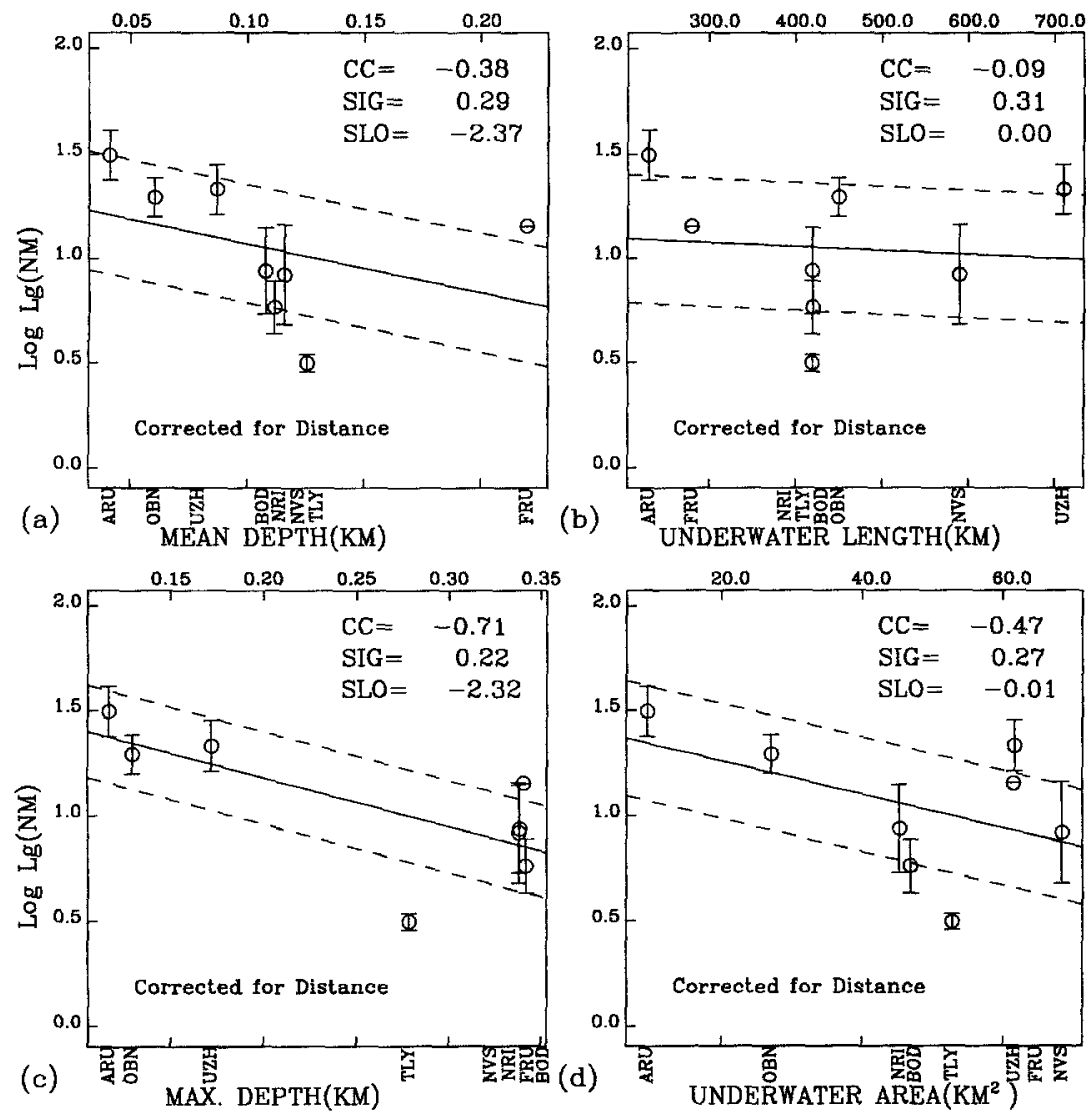

Figure 9. Correlation of rms $L_{g}$ amplitudes from the Novaya Zemlya explosions with four parameters that characterize the underwater segments of each path, mean depth, underwater length, maximum depth, and underwater area. The data are mean values on each path, after equalizing the source strengths to a common $m_{b}=5.0$, and correcting for distance. The geometrical spreading factor for $L_{g}$ is approximated by the power law $r^{-5 / 6}$ (Nuttli, 1973).
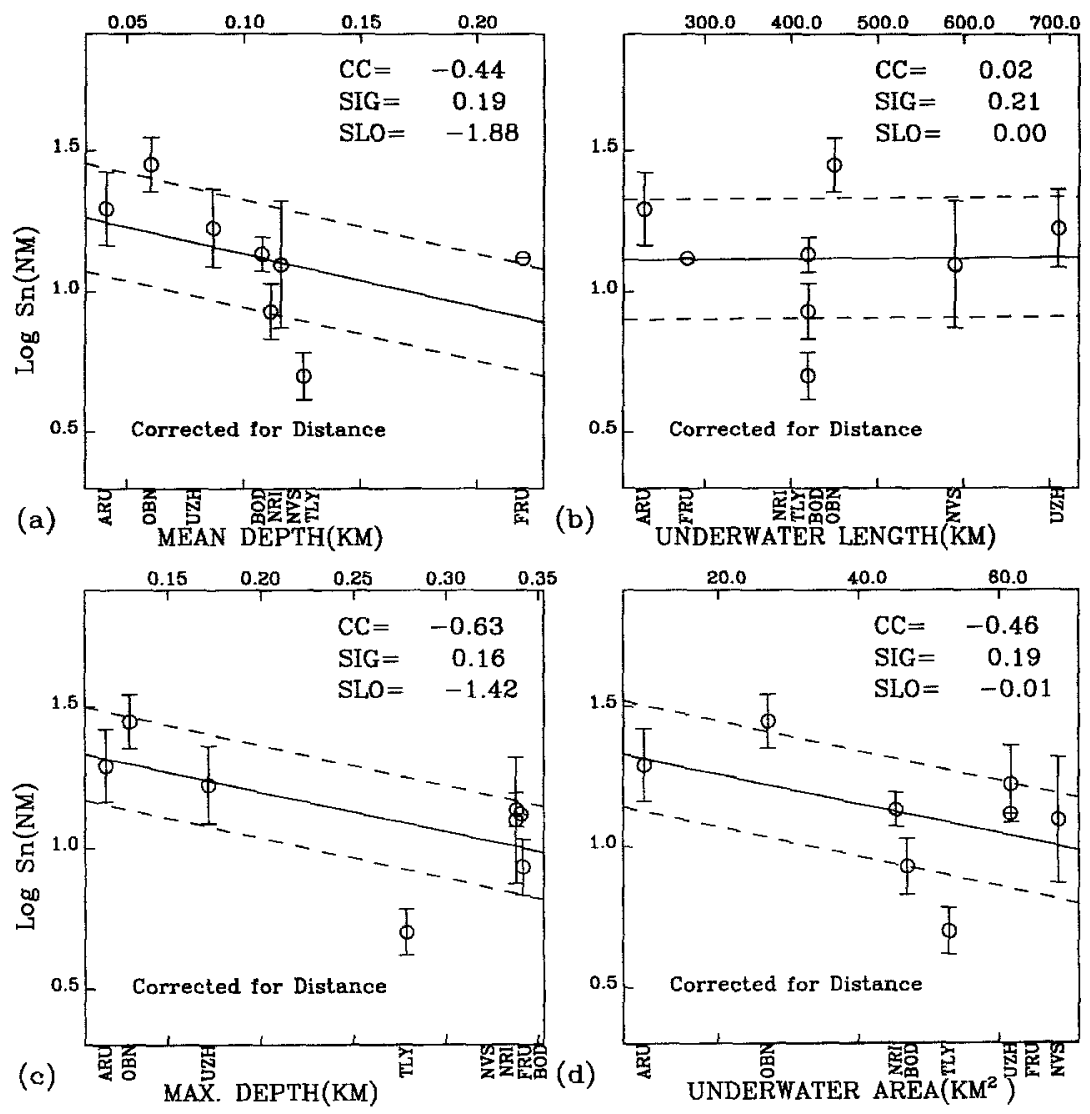

Figure 10. Similar to Figure 9 but for $S_{n}$ amplitudes. The $r^{-5 / 6}$ correction is still used. The results are close to those in Figure 9, but the correlation and trend with maximum depth are a little weaker. 
The direct 0 - to 5 -sec $P$-wave rms amplitude has no correlation with the water depth, as expected. Note that station TLY, a consistent outlier for both $S_{n}$ and $L_{g}$, is also low for $P$, suggesting a receiver site effect or possibly an error in the instrument corrections and/or gains provided in the data exchange.

Given the complex nature of geometric spreading and path effects, we can better explore energy partitioning by examing rms ratios. Ratios are also of importance because ratios such as $P / L_{g}$ are being explored as the main regional discriminant between nuclear explosions and earthquakes. We seek to establish whether such ratios are affected by the water segment. We expect that ratios for regional phases may be affected by average path properties, as shown in Figure 8, and we can explore whether applying corrections for the on-land portion of the paths enhances the sensitivity to the underwater segments. Figure 12 shows results for the $S_{n} / L_{g}$ ratios, correlated with the four underwater parameters. The $S_{n} / L_{g}$ has a fairly strong relationship with maximum depth, which can be attributed to the stronger trend in Figure 9 versus Figure 10. Note that the elimination of any site effect for TLY tightens up the trend. Also note that the single observation at FRU should be downweighted.

From Figure 1 it is clear that the on-land path segments are much longer than the underwater segments.
We use the correlations between $S_{n} / L_{g}$ and $P / L_{g}$ and onland topographic roughness of the path found in our previous study (Zhang and Lay, 1994) to make corrections for on-land roughness for the Novaya Zemlya data. Since the range in path roughness is relatively small (see Fig. 8 ), these corrections are not very large, but one should observe an improvement in the correlations with underwater properties if the on-land contributions are in fact suppressed. The results for $S_{n} / L_{g}$ after correction for roughness (relative to the path to ARU) are shown in Figure 13. The correlations of $S_{n} / L_{g}$ ratios with mean depth, maximum depth, and water area are all actually improved, lending credibility to the influence of the underwater segment. The strong effect associated with water depth does in fact appear to be responsible for the poor correlation with overall path roughness for these data found in Figure 8.

Since $L_{g}$ shows a trend with underwater properties, while the $0-$ to $5-\sec P$ window does not, the presence of correlations in the $P / L_{g}$ ratio (Fig. 14) is no surprise. Because the Semipalatinsk data span comparable distance ranges, it is possible to use the relationship found by Zhang and Lay (1994) for $P / L_{g}$ versus continental path roughness to make a correction, but this effectively corrects only for the $L_{g}$ wave. It is interesting to see (Fig. 15) that application of this correction does in fact reduce the scatter in the relationship with the underwater path

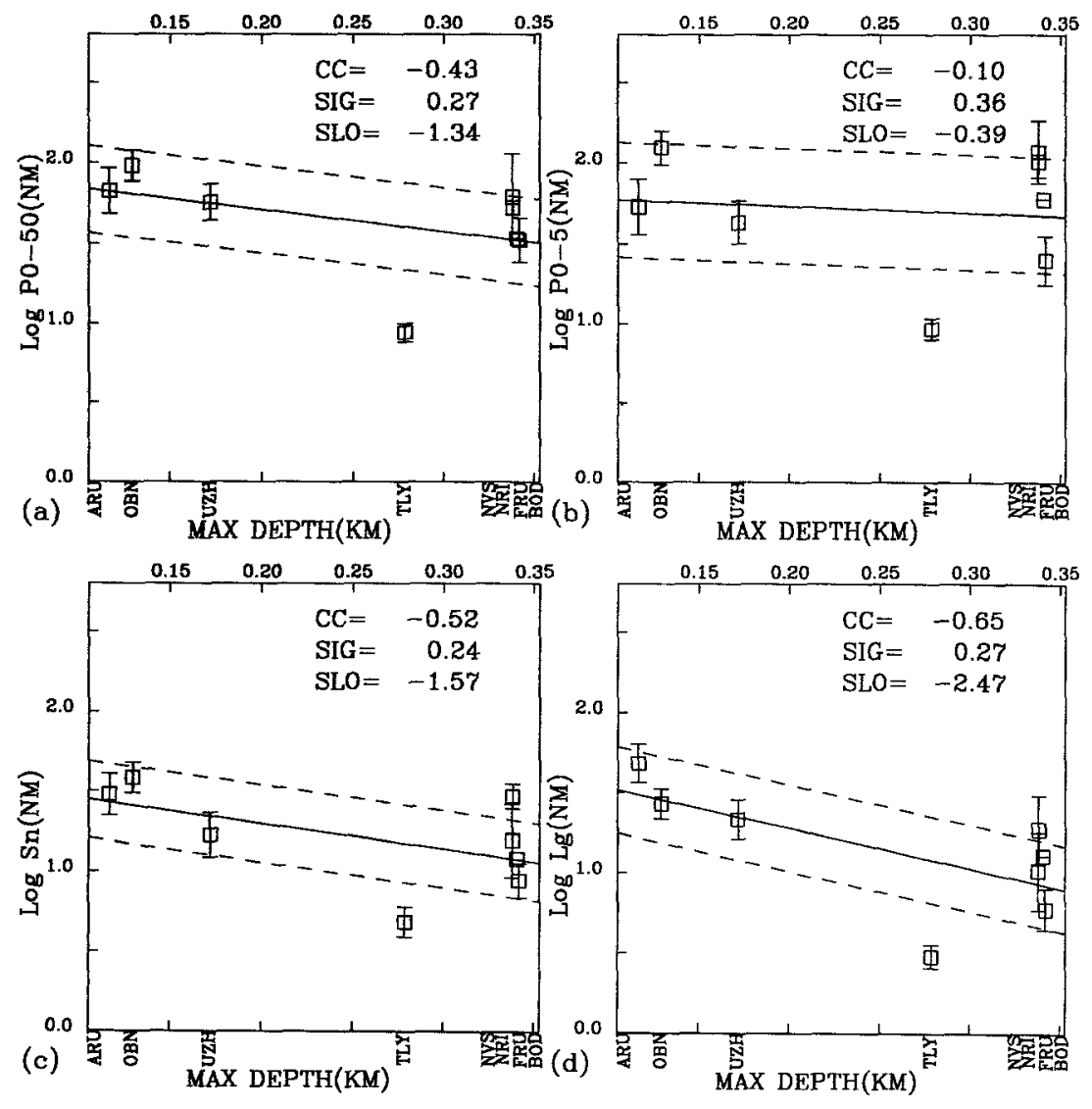

Figure 11. (a) through (d) Comparison of relationships between rms amplitude measurements for different phases in the short-period signals and maximum water depth on each path. No distance corrections are applied to any of the phases in this case. The direct $P$ window, measured for the first $5 \mathrm{sec}$ of the waveform, is shown in (b), and no relationship to the water depth is seen. A weak trend is found for a long, 0 - to 50 sec $P$ window, which includes substantial coda, and stronger trends are found for $S_{n}$ and $L_{g}$. 


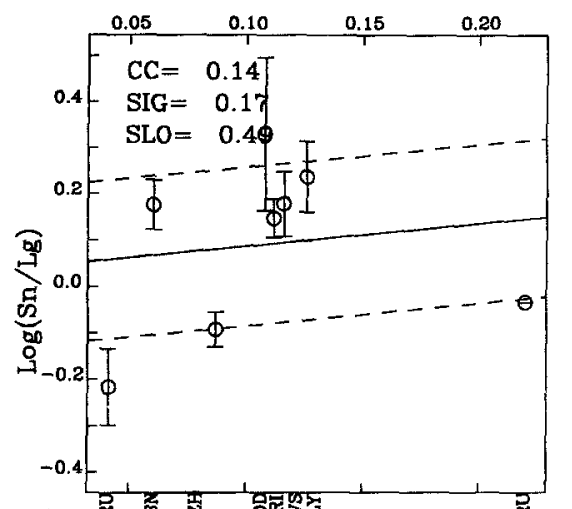

(a)
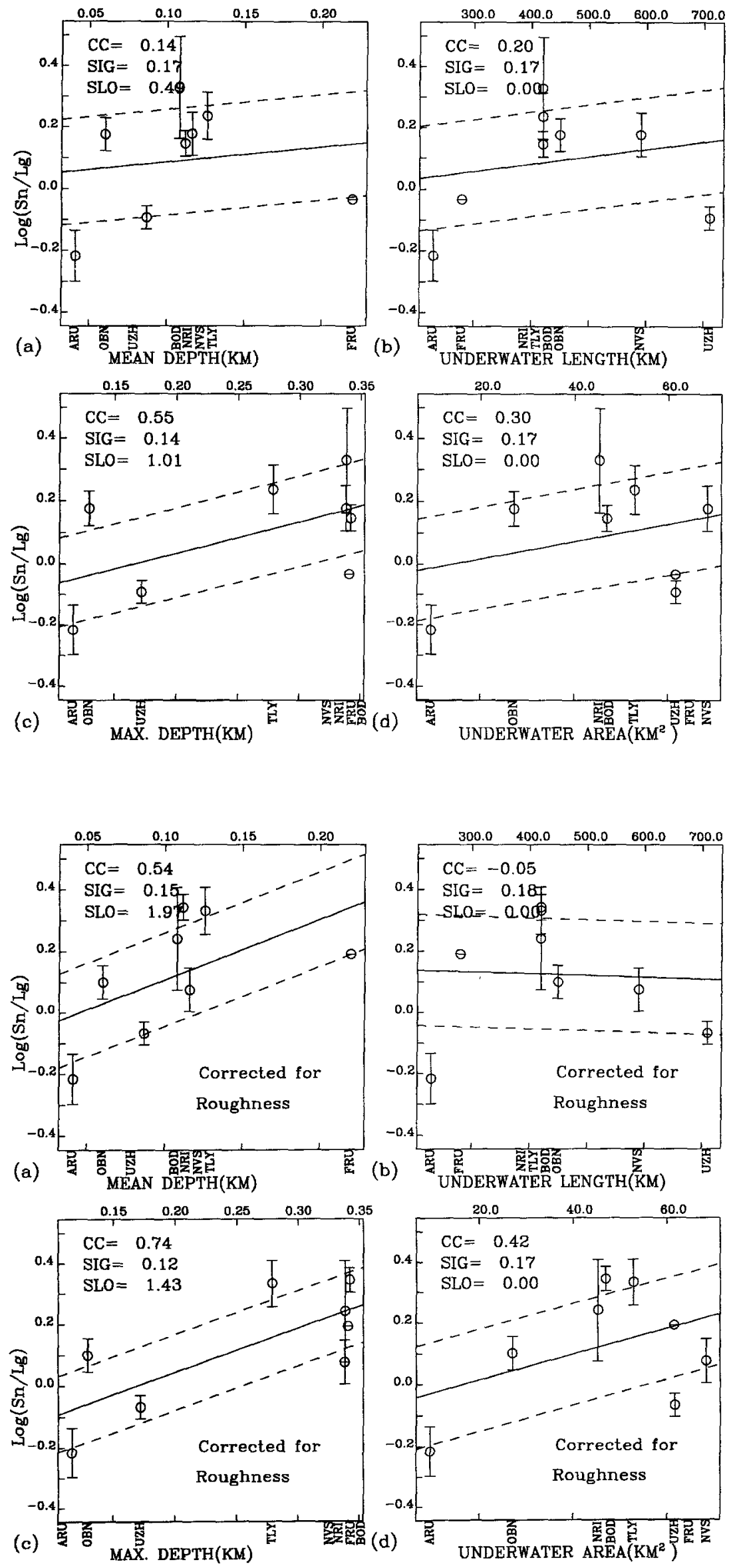

Figure 12. Correlations between $S_{n} / L_{g}$ ratios and the four underwater path parameters.
Figure 13. Similar to Figure 12, but now the $S_{n} / L_{g}$ ratios have been corrected for relative path roughness, using the continental path correlations found for Semipalatinsk data by Zhang and Lay (1994). 

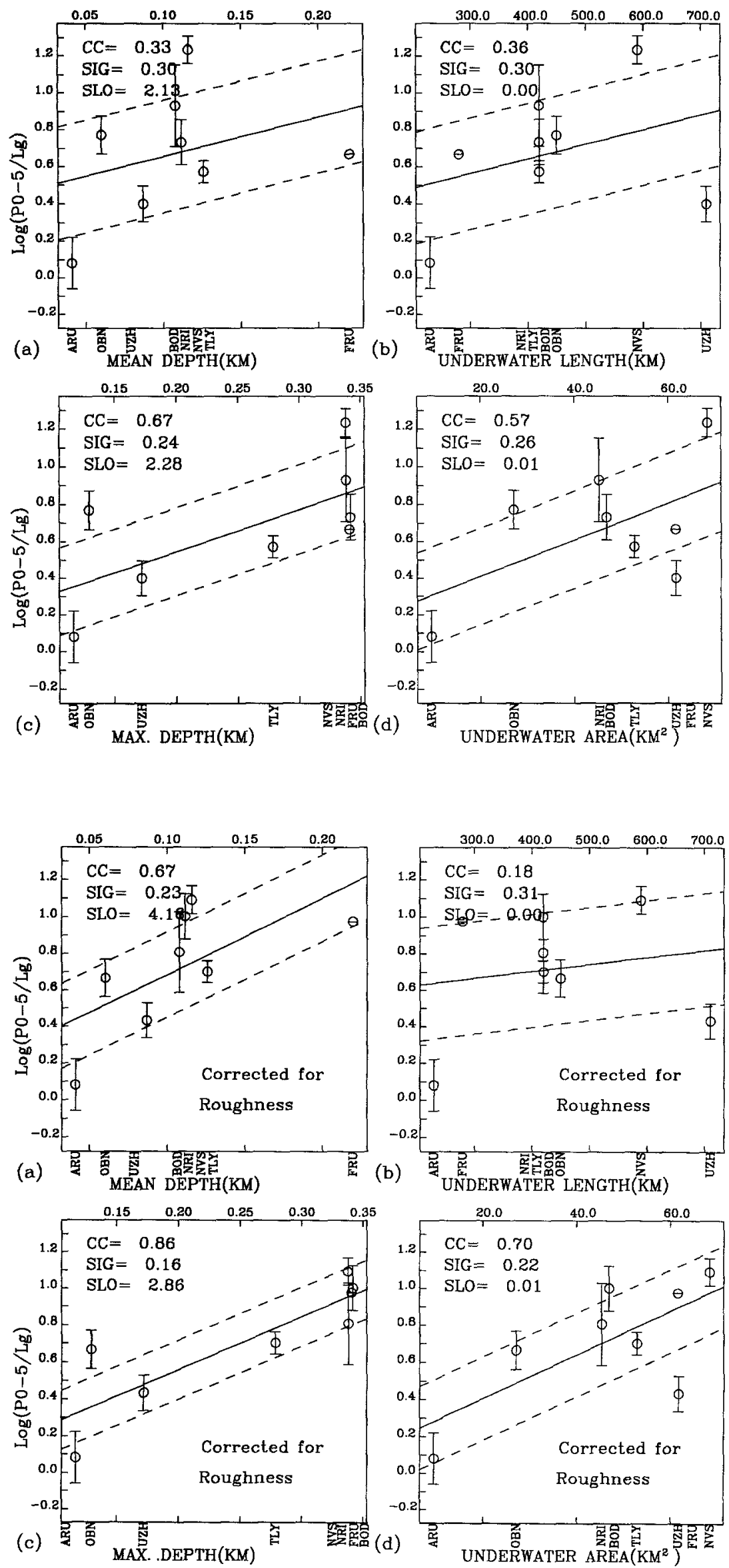

Figure 14. Correlations between $P / L_{g}$ and the four underwater path parameters.
Figure 15. Similar to Figure 14, but now the $P / L_{g}$ ratios have been corrected for relative path roughness, using the continental path correlations found for Semipalatinsk data by Zhang and Lay (1994). 
properties, with the best correlation again being with maximum depth. Similar results are found for the 0 - to 50 -sec $P$-wave window. While these data are at larger distances than conventionally used in regional discrimination efforts (based on $P n / L_{g}$ ), these results hold much promise for comparable efforts to reduce scatter in discriminant ratios used for nonproliferation monitoring.

\section{Discussion and Conclusions}

This study indicates that $L_{g}$ energy is lost when traversing an underwater continental margin, possibly accompanied by a corresponding increase in $S_{n}$ energy. Studies by Isacks and Stephens (1975), Chinn et al. (1980), and Ni and Barazangi (1983) have discussed socalled "early $L_{g}$ " phases in the $S_{n}$ coda, which arrive several seconds ahead of the $3.5 \mathrm{~km} / \mathrm{sec}$ group velocity arrival time. Baumgardt (1990) also observed early $L_{g}$ in his study of data at NORESS and Graefenburg arrays for Novaya Zemlya sources. He argues that the primary mechanism for energy partitioning is $L_{g}$-to- $S_{n}$ and $S_{n}$-to$L_{g}$ scattering. Our study emphasizes the important role played by the underwater path, and we agree that $L_{g}$-to$S_{n}$ and $S_{n}$-to- $L_{g}$ scattering probably plays some role in the propagation. This could explain the enhanced $S_{n} / L_{g}$ ratios of the Novaya Zemlya observations relative to Semipalatinsk data. However, it is important to note that the trends in $S_{n} / L_{g}$ and $P / L_{g}$ ratios versus bathymetric parameters in Figures 13 and 15 may be primarily an $L_{g}$ effect. Moreover, it is not possible for us to confidently isolate the location of any conversions that do take place, other than to say that it must be in the general vicinity of the source or receivers, given our gross group velocity windowing procedure.

The Barents Sea and Kara Sea are similar shallow basins. Gramberg (1988) identifies two defining characteristics of the central Barents basin. One is thinning of the crust by about $10 \mathrm{~km}$ (Fig. 16b). Another is the "missing granitic layer." The data that Baumgardt (1990) analyzes traverse the central Barents Sea, where significant crustal thinning is expected. In our data set the three paths sampling the Barents Sea cross the Pechora plate, in the southeast region of the basin, where the crustal thickness is about $35 \mathrm{~km}$. Bogolepov et al. (1990) studied the structure of the Kara Sea basin with a combination of magnetic, gravitational, and seismic refraction data. They find similar characteristics in the center of south Kara syncline (Fig. 16c) to the central Barents Sea. The depth of the Moho varies from 32 to $35 \mathrm{~km}$ in the near-shore region to 26 to $28 \mathrm{~km}$ in the central Kara syncline. The depth of the Conrad discontinuity varies from 30 to 22 to $25 \mathrm{~km}$. In the central region, the crystalline granitic complex is replaced by a gabbroic complex. Another characteristic is the complex geometry of the granitic basement, with extensive folding, metamorphism and imbricate structure. Four of our paths, to
BOD, NRI, TLY, and NVS cross the central Kara Sea basin, while the last two, to FRU and ARU, traverse the Ural-Novaya Zemlya fold belt. We observe significant reductions in $L_{g}$ amplitudes for the paths across the Kara Sea.

The $L_{g}$ phase can be viewed as a guided wave in the crust, very dependent upon the lateral continuity of the wave guide. Given that disruptions of the wave guide are expected near continental margins, and even within tectonically active continental regions, there are many concerns about the reliability of $L_{g}$ in discrimination measurements (e.g., Kennett, 1989), independent of its remarkable relative stability on a given path for relative yield estimation (e.g., Ringdal et al., 1992; Hansen et al., 1990). Crustal thinning apparently can reduce $L_{g}$

(a)
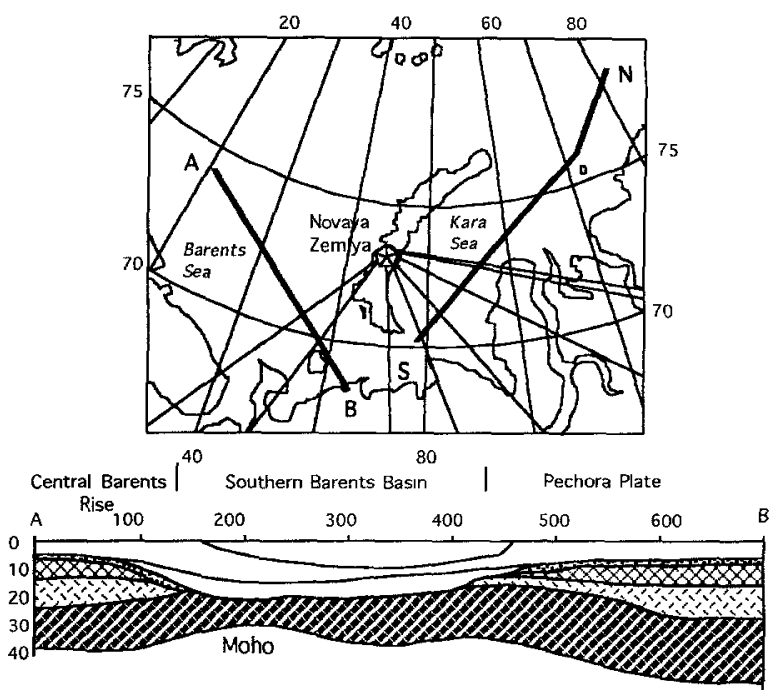

(c)
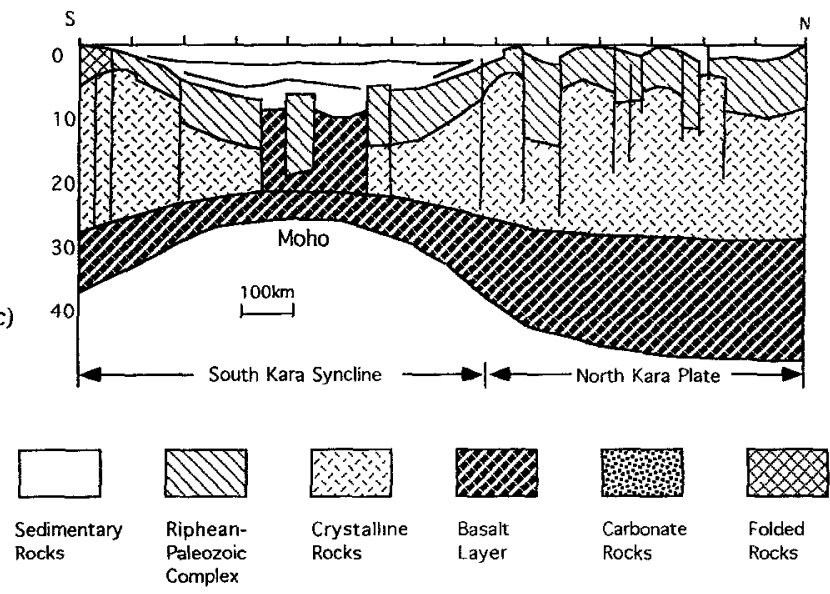

Figure 16. (a) Map of the adjacent region of the islands of Novaya Zemlya, showing two lines of cross section and eight paths. (b) NW-SE cross section, labeled A-B in (a), across the southeastern part of the Barents Sea basin (after Gramberg, 1988). (c) NE-SW cross section of the Kara Sea basin (after Bogolepov et al., 1990), labeled N-S in (a), across the North Kara plate and south Kara syncline. 
amplitude (Cao and Muirhead, 1993). Thus, we may explain the systematic trends between the Barents group and Kara group as a result of variable degree of blockage associated with thinning of the crustal wave guide. However, the precise mechanisms involved are subject to debate.

It is quite possible that sediment thickness variations in the basins influence $L_{g}$ blockage, but we do not have a robust procedure for separating the effects of crustal thinning and sediment thickness, which are strongly correlated. Maximum water depth, the parameter yielding the strongest relationships with $L_{g}$ amplitudes, is strongly affected by near-surface geology, such as the sediment thickness in the basins. Some information is available about the thickness of sedimentary basins, along with Moho depth along the paths sampled by our data, mainly from Deep Seismic Sounding and seismic reflection profiling as well as other geological and geophysical data (Kunin and Sheykh-Zade, 1983; Kunin, 1986). This information has been digitized and made available by the Cornell Institute for Studies of the Continents, with $0.25^{\circ}$ resolution. Figure 17 shows the relationships between $L_{g}$ amplitudes, corrected for geometric spreading, and maximum water depth (Fig. 17a), minimum crustal thickness (Fig. 17b), and maximum sedimentary layer thickness (Fig. 17c) along each path. While the data set is limited, the strongest variation is found with water depth, and no trend is apparent with minimum crustal thickness, which basically measures the necking of the crust along the continental margin. However, the latter parameter is not well sampled by our particular data set. For other data sets (Zhang, Schwartz, and Lay, 1994), crustal necking does appear to strongly affect $L_{g}$ amplitudes. Sediment layer thickness is associated with a weak trend, but the statistical significance is low. The precise mechanism by which the $L_{g}$ energy is lost requires further study. The complex structure of the crystalline basement may account for some of the observed behavior, such as the low amplitudes of both $L_{g}$ and $S_{n}$ along the path to TLY (Fig. 11).

The foregoing discussion has emphasized the possible elastic scattering effects of the disrupted wave guide. There is no question that attenuation is very important for $L_{g}$ and $S_{n}$ phases as well, and it would be very attractive to correct our data for attenuation variations on the different paths. Many efforts have evaluated frequency-dependent attenuation of $L_{g}$ in western Europe (e.g., Nicolas et al., 1982; Campillo et al., 1985; Campillo, 1987) and Eurasia (Nuttli, 1980, 1981; Chun et al., 1992). Analysis of $L_{g}$ coda also provides constraints on the $L_{g}$ quality factor (e.g., Xie and Mitchell, 1990, 1991; Pan et al., 1992; Mitchell et al., 1993). The $L_{g}$ coda $Q$ values agree well with $L_{g} Q$ values in some cases (Mitchell et al., 1993). We use the Eurasian $L_{g}$ coda $Q$
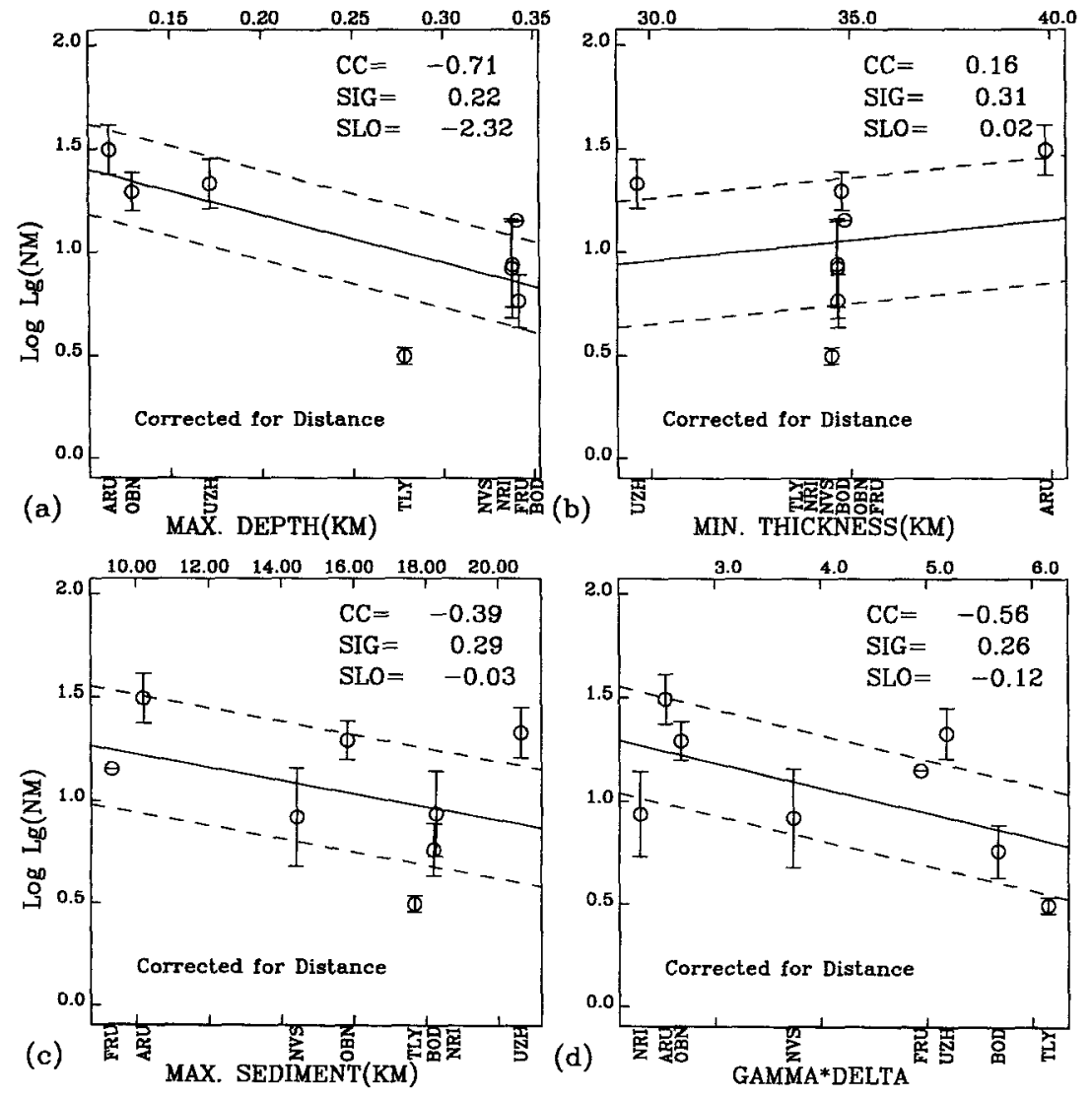

Figure 17. The relationships between $L_{g}$ amplitudes, corrected for geometric spreading, and (a) maximum water depth, (b) minimum crustal thickness, (c) maximum sedimentary layer thickness, and (d) the attenuation term $\gamma \Delta$ along each path. 
map of Pan et al. (1992) to determine the exponential attenuation term $\gamma \Delta$ (Nuttli, 1986) for a frequency of 1 $\mathrm{Hz}$ for each of our paths (Fig. 17d). There is a clear correlation with $\log L_{g}$, as expected, but the trend is quite a bit weaker than expected (the expected slope is - log (e) $=-0.43$ ). If we apply the attenuation corrections, using the simplifying approximation that our rms values are representative of the $1-\mathrm{Hz}$ amplitudes, the $L_{g}$ amplitudes no longer show any trend with bathymetric properties. However, our feeling is that the $Q$ model has the right geographic pattern, but it overpredicts attenuation variations on the different paths, when applied to $L_{g}$ directly, as suggested by the low slope seen in Figure $17 \mathrm{~d}$. Thus, we have not used corrected $L_{g}$ amplitudes in our attempt to detect underwater path effects. We found that $S_{n}$ amplitudes show a strong trend with the $L_{g}$ coda $Q$ variations for Novaya Zemlya, but the $S_{g} / L_{g}$ ratios do not vary with $\gamma \Delta$ for either test site, so it is not likely that attenuation plays a key role in the strong patterns seen in Figure 8. It is not clear how to correct the $S_{n}$ data for attenuation, but there is a clear suggestion that $S_{n}$ attenuation is linked to the $L_{g}$ coda $Q$ variations. This suggests coupling of upper mantle and crustal attenuation, and raises the possibility that the $L_{g}$ coda $Q$ model may include a mantle component that overcorrects the $L_{g}$ phases. Until we have independent models for $S_{n}$ attenuation we cannot proceed further, but it is clear that attenuation is an important factor influencing the regional phase-amplitude ratios, and significant progress is being made in mapping out the attenuation variations (Pan et al., 1992).

Since we generally lack detailed knowledge of crustal structure for paths traversed by regional phases used in nonproliferation monitoring, we have explored the possibility of developing empirical path calibration procedures. Water depth proved to be the most effective elastic path characteristic for the Novaya Zemlya data set, presumably since it serves as a surrogate for the deep structure of the shallow sea basin. Relative to the reference data set provided by Semipalatinsk recordings, almost all Novaya Zemlya data exhibit a shift of the peak energy toward the $S_{n}$ window, whether the maximum water depth is 100 or $300 \mathrm{~m}$. This indicates that an amplitude correction is generally needed for wave paths that cross marginal seas. In addition, 200 -m water-depth differences can reflect variations in crustal thickness and sediment thickness, causing $L_{g}$ amplitudes to vary. Using empirical corrections should enable significant reduction in the scatter of both $S_{n} / L_{g}$ and $P / L_{g}$ amplitude ratios. Combined with empirical corrections for topography along the on-land paths and corrections for laterally varying attenuation models in the crust and upper mantle, reduced scatter in such measurements may improve nonproliferation monitoring efforts in diverse crustal environments.

\section{Acknowledgments}

The waveform data set used here was made available by Dr. Alan Ryall. We thank Dr. Hans Israelsson for extensive information about the instrument responses, and Dr. Susan Schwartz for helping to resolve some problems with the data. Dr. Douglas Baumgardt and an anonymous reviewer provided helpful comments on the manuscript. Dr. Xie and Dr. Pan kindly allowed us to use their $L_{g}$ coda $Q$ model. This research was supported by the W. M. Keck Foundation, the Air Force Office of Scientific Research, under Grant Number F49620-92$\mathrm{J}-0461$, and the Defense Advanced Research Projects Agency, under Contract Number F29601-91-K-DB21. This is contribution number 212 of the Institute of Tectonics and the C. F. Richter Seismological Laboratory.

\section{References}

Baumgardt, D. R. (1990). Investigation of teleseismic $L_{8}$ blockage and scattering using regional arrays, Bull. Seism. Soc. Am. 80, $2261-2281$.

Bogolepov, A. K., V. A. Zhuravlev, E. U. Shipilov, and A. Y. Yunov (1990). New data on the deep structure of the Kara Sea (from results of complex geological and geophysical study), Dokl. Akad. Nauk SSSR 315, 159-162 (in Russian).

Campillo, M., J. L. Plantet, and M. Bouchon (1985). Frequencydependent attenuation in the crust beneath central France from $L_{g}$ waves: data analysis and numerical modeling, Bull. Seism. Soc. Am. 75, 1395-1411.

Campillo, M. (1987). $L_{g}$ wave propagation in a laterally varying crust and the distribution of the apparent quality factor in central France, J. Geophys. Res. 92, 12604-12614.

Cao, S. and K. J. Muirhead (1993). Finite difference modeling of $L_{z}$ blockage, Geophys. J. Int. 116, 85-96.

Chinn, D. S., B. L. Isacks, and M. Barazangi (1980). High-frequency seismic wave propagation in western South America along the continental margin, in the Nazca Plate and across the Altiplano, Geophys. J. R. Astr. Soc, 60, 329-344.

Chun, K.-Y., T. F. Zhu, and X. R. Shih (1992). Time domain analysis of $L_{g}$ wave attenuation in Eurasia, in Reginal Wave Attenuation in Eurasia, Scientific Report No. 2, DARPA/NMRO, Arlington, Virginia, 3-12.

Gramberg, I. S. (1988). The Barents Shelf Plate, Vol. 196, Nedra, Leningrad, USSR, 218, (in Russian).

Gregersen, S. (1984). $L_{8}$ wave propagation and crustal structure differences near Denmark and the North Sea, Geophys. J. R. Astr. Soc. 79, 217-234.

Hansen, R. A., F. Ringdal, and P. G. Richards (1990). The stability of RMS $L_{g}$ measurements and their potential for accurate estimation of the yields of Soviet underground nuclear explosions, Bull. Seism. Soc. Am. 80, 2106-2126.

Isacks, B. L. and C. Stephens (1975). Conversion of $S_{n}$ to $L_{g}$ at a continental margin, Bull. Seism. Soc. Am. 65, 224-235.

Israelsson, H. (1992). RMS $L_{g}$ as a yield estimation in Eurasia, Final Technical Report for AF Phillips Laboratory, Hanscom AFB, Massachusetts.

Kadinsky-Cade, K., M. Barazangi, J. Oliver, and B. Isacks (1981). Lateral variations of high-frequency seismic wave propagation at regional distances across the Turkish and Iranian Plateaus, $\boldsymbol{J}$. Geophys. Res. 86, 9377-9396.

Kennett, B. L. N. (1986). $L_{g}$ waves and structural boundaries, Bull. Seism. Soc. Am. 76, 1133-1141.

Kennett, B. L. N. (1989). On the nature of regional seismic phasesI, phase representations for $P n, P g, S_{n}, L_{\xi}$, Geophys J. Int. 98, 447-456.

Kennett, B. L. N. and S. Mykkeltveit (1984). Guided wave propa- 
gation in laterally varying media-II, $L_{g}$-waves in north-western Europe, Geophys. J. R. Astr. Soc. 79, 257-267.

Kennett, B. L. N., S. Gregersen, S. Mykkeltveit, and R. Newmark (1985). Mapping of crustal heterogeneity in the North Sea basin via the propagation of $L_{g}$-waves, Geophys. J. R. Astr. Soc. 83, 299-306.

Kunin, N. Ya. and E. R. Sheykh-Zade (1983). New data on lateral inhomogeneities in the upper mantle under western Eurasia, Dokl. Akad. Nauk. USSR. 273, 1087-1091.

Kunin, N. Ya. (1986). The basic morphostructures on the surface of the upper mantle under the Asiatic continent, Izv. Akad. Nauk USSR. Earth Phys. 22, 349-357.

Lynnes, C. and R. Baumstark (1991). Phase and spectral ratio discrimination in North America, Final Technical Report, PL-TR91-2212(II) Phillips Laboratory, Hanscom, AFB, Massachusetts.

Maupin, V. (1989). Numerical modeling of $L_{g}$ wave propagation across the North Sea central graben, Geophys. J. Int. 99, 273-283.

Mitchell, B. J., J. Xie, Y. Pan, and J. Ni (1993). $L_{g} Q, L_{g}$ coda $Q$ and yield estimation in Eurasia, in Proc. of the 15th Annual PL/ Arpa Seismic Research Symposium, Phillips Laboratory, Hanscom AFB, Massachusetts, 277-283.

$\mathrm{Ni}$, J. and M. Barazangi (1983). High-frequency seismic wave propagation beneath the Indian Shield, Himalayan Arc, Tibetan Plateau and surrounding regions: high uppermost mantle velocities and efficient $S_{n}$ propagation beneath Tibet, Geophys. J. R. Astr. Soc. 72, 665-689.

Nicolas, O. W., B. Mechler, and M. Bouchon (1982). Attenuation of regional phases in western Europe, Bull. Seism. Soc. Am. 72, 2089-2106.

Nuttli, O. W. (1973). Seismic wave attenuation and magnitude relations for eastern North America, J. Geo Phys. Res. 78, 876885.

Nuttli, O. W. (1980). The excitation and attenuation of seismic crustal phases in Iran, Bull. Seism. Soc. Am. 70, 469-485.

Nuttli, O. W. (1981). On the attenuation of $L_{g}$ waves in western and central Asia and their use as a discriminant between earthquakes and explosions, Bull. Seism. Soc. Am. 71, 249-261.

Nuttli, O. W. (1986). Yield estimates of Nevada test site explosions obtained from seismic $L_{g}$ waves, J. Geophys. Res. 91, 21372151.

Nuttli, O. W. (1988). $L_{g}$ magnitudes and yield estimates for underground Novaya Zemlya explosions, Bull. Seism. Soc. Am. 78 , 873-884.

Oliver, J., M. Ewing, and F. Press (1955). Crustal structure of the Arctic regions from the $L_{3}$ phase, Bull. Geolo. Soc. Am. 66, $1063-1074$
Pan, Y., B. J. Mitchell, J. Xie, and J. Ni (1992). $L_{g}$ coda $Q$ across northern Eurasia, in Proc. of the 14th Annual PL/Darpa Seismic Research Symposium, PL-TR-92-2210, Phillips Laboratory, Hanscom AFB, Massachusetts, 311-317.

Pomeroy, P. W., W. J. Best, and T. J. McEvilly (1982). Test ban treaty verification with regional data-a review, Bull. Seism. Soc. Am. 72, S89-S129.

Press, F. and M. Ewing (1952). Two slow surface waves across North America, Bull. Seism. Soc. Am. 42, 219-228.

Regan, J. and D. G. Harkrider (1989). Seismic representation theorem coupling: synthetic SH mode sum seismograms for non-homogeneous paths, Geophys. J. R. Astr. Soc. 98, 429-446.

Ringdal, F. and J. Fyen (1991). RMS $L_{g}$ analysis of Novaya Zemlya explosion recordings, Semiannual Technical Summary, 1 October 1990-31 March 1991, NORSAR Scientific Report No. 290/91. NTNF/NORSAR, Kjeller, Norway.

Ringdal, F., P. D. Marshall, and R. W. Alewine (1992). Seismic yield determination of Soviet underground nuclear explosions at the Shagan River test site, Geophys. J. Int. 109, 65-77.

Ruzaikin, A. I., I. L. Nersesov, V. I. Khalturin, and P. Molnar (1977). Propagation of $L_{g}$ and lateral variations in crustal structure in Asia, J. Geophys. Res. 82, 307-316.

Savarensky, E. and N. Valdner (1960). Observations of $L_{g}$ and $R_{g}$ waves from the Black Sea basin earthquakes, Ann. Geofis. 13, 129-134.

Wessel, P. and W. H. F. Smith (1991). Free software helps map and display data, display, $\operatorname{EOS} 72,441,445-446$.

Wetmiller, R. J. (1974). Crustal structure of Baffin Bay from earthquake generated $L_{g}$ phases, Can. J. Earth Sci. 11, 123-130.

Xie, J. and B. J. Mitchell (1990). A back-projection method for imaging large-scale lateral variations of $L_{g}$ and coda $Q$ with application to continental Africa, Geophys. J. Int. 100, 161-181.

Xie, J. and B. J. Mitchell (1991), $L_{g}$ coda $Q$ across Eurasia, in Yield and Discrimination Studies in Stable Continental Regions, Technical Report PL-TR-91-2286. ADA 251590.

Zhang, T. and T. Lay (1994). Analysis of short-period regional phase path effects associated with topography in Eurasia, Bull. Seism. Soc. Am. 84, 119-132.

Zhang, T., S. Y. Schwartz, and T. Lay (1994). Multivariate analysis of waveguide effects on short-period regional wave propagation in Eurasia and its application in seismic discrimination, J. Geophys. Res. (submitted for publication).

University of California

Santa Cruz, California 95064

Manuscript received 28 June 1993. 